\title{
Associations of low grade inflammation and endothelial dysfunction with depression - The Maastricht Study
}

Citation for published version (APA):

van Dooren, F. E. P., Schram, M. T., Schalkwijk, C. G., Stehouwer, C. D. A., Henry, R. M. A., Dagnelie, P. C., Schaper, N. C., van der Kallen, C. J. H., Koster, A., Sep, S. J. S., Denollet, J., Verhey, F. R. J., \& Pouwer, F. (2016). Associations of low grade inflammation and endothelial dysfunction with depression The Maastricht Study. Brain Behavior and Immunity, 56, 390-396.

https://doi.org/10.1016/j.bbi.2016.03.004

Document status and date:

Published: 01/08/2016

DOI:

10.1016/j.bbi.2016.03.004

Document Version:

Publisher's PDF, also known as Version of record

Document license:

Taverne

Please check the document version of this publication:

- A submitted manuscript is the version of the article upon submission and before peer-review. There can be important differences between the submitted version and the official published version of record.

People interested in the research are advised to contact the author for the final version of the publication, or visit the DOI to the publisher's website.

- The final author version and the galley proof are versions of the publication after peer review.

- The final published version features the final layout of the paper including the volume, issue and page numbers.

Link to publication

\footnotetext{
General rights rights.

- You may freely distribute the URL identifying the publication in the public portal. please follow below link for the End User Agreement:

www.umlib.nl/taverne-license

Take down policy

If you believe that this document breaches copyright please contact us at:

repository@maastrichtuniversity.nl

providing details and we will investigate your claim.
}

Copyright and moral rights for the publications made accessible in the public portal are retained by the authors and/or other copyright owners and it is a condition of accessing publications that users recognise and abide by the legal requirements associated with these

- Users may download and print one copy of any publication from the public portal for the purpose of private study or research.

- You may not further distribute the material or use it for any profit-making activity or commercial gain

If the publication is distributed under the terms of Article 25fa of the Dutch Copyright Act, indicated by the "Taverne" license above, 
Full-length Article

\title{
Associations of low grade inflammation and endothelial dysfunction with depression - The Maastricht Study
}

\author{
Fleur E.P. van Dooren a,c,d,*, Miranda T. Schram ${ }^{\mathrm{a}, \mathrm{b}}$, Casper G. Schalkwijk ${ }^{\mathrm{a}, \mathrm{b}}$, Coen D.A. Stehouwer ${ }^{\mathrm{a}, \mathrm{b}}$, \\ Ronald M.A. Henry ${ }^{\mathrm{a}, \mathrm{b}}$, Pieter C. Dagnelie ${ }^{\mathrm{b}, \mathrm{f}, \mathrm{g}}$, Nicolaas C. Schaper ${ }^{\mathrm{a}, \mathrm{b}, \mathrm{f}}$, Carla J.H. van der Kallen ${ }^{\mathrm{a}, \mathrm{b}}$, \\ Annemarie Koster ${ }^{\text {e,f }}$, Simone J.S. Sep ${ }^{\mathrm{a}, \mathrm{b}}$, Johan Denollet ${ }^{\mathrm{c}}$, Frans R.J. Verhey ${ }^{\mathrm{d}}$, Frans Pouwer ${ }^{\mathrm{c}}$ \\ a Department of Internal Medicine, Maastricht University Medical Centre, Maastricht, The Netherlands \\ ${ }^{\mathrm{b}}$ CARIM Cardiovascular Research Institute Maastricht, Maastricht University, Maastricht, The Netherlands \\ ${ }^{\mathrm{C}}$ CoRPS - Center of Research on Psychological and Somatic disorders, Department of Medical and Clinical Psychology, Tilburg University, Tilburg, The Netherlands \\ ${ }^{\mathrm{d}}$ MHeNS - Alzheimer Centre Limburg, School for Mental Health and Neuroscience, Maastricht University, Maastricht, The Netherlands \\ ${ }^{\mathrm{e}}$ Department of Social Medicine, Maastricht University, Maastricht, The Netherlands \\ ${ }^{\mathrm{f}}$ CAPHRI School for Public Health and Primary Care, Maastricht University, Maastricht, The Netherlands \\ ${ }^{\mathrm{g}}$ Department of Epidemiology, Maastricht University, Maastricht, The Netherlands
}

\section{A R T I C L E I N F O}

\section{Article history:}

Received 30 December 2015

Received in revised form 29 February 2016

Accepted 8 March 2016

Available online 9 March 2016

\section{Keywords:}

Depression

Inflammation

Endothelial dysfunction

Lifestyle factors

\begin{abstract}
A B S T R A C T
Background: The pathogenesis of depression may involve low-grade inflammation and endothelial dysfunction. We aimed to evaluate the independent associations of inflammation and endothelial dysfunction with depressive symptoms and depressive disorder, and the role of lifestyle factors in this association.

Methods: In The Maastricht Study, a population-based cohort study ( $\mathrm{n}=852,55 \%$ men, $\mathrm{m}=59.8 \pm 8.5$ years), depressive symptoms were assessed with the Patient Health Questionnaire-9 and (major and minor) depressive disorder with the Mini-International Neuropsychiatric Interview. Plasma biomarkers of inflammation (hsCRP, SAA, sICAM-1, IL-6, IL-8, TNF- $\alpha$ ) and endothelial dysfunction (sVCAM-1, sICAM-1, sE-selectin, vWF) were measured with sandwich immunoassays and combined into two standardized sum scores.

Results: Biomarkers of inflammation (hsCRP, TNF- $\alpha$, SAA, sICAM-1) and endothelial dysfunction (sICAM-1, sE-Selectin) were univariately associated with depressive symptoms and depressive disorder. The sum scores of inflammation and endothelial dysfunction were associated with depressive disorder after adjustment for age, sex, type 2 diabetes, kidney function and prior cardiovascular disease (OR 1.54, $p=0.001$ and $1.40, p=0.006$ ). Both sum scores remained significantly associated with depressive disorder after additional adjustment for lifestyle factors smoking, alcohol consumption and body mass index. The sum score of inflammation was also independently associated with depressive symptoms, while the sum score of endothelial dysfunction was not.

Conclusions: Inflammation and endothelial dysfunction are both associated with depressive disorder, independent of lifestyle factors. Our results might suggest that inflammation and endothelial dysfunction are involved in depression.
\end{abstract}

(c) 2016 Published by Elsevier Inc.

\section{Introduction}

Depression is a complex disorder with a highly variable course, an inconsistent response to treatment, and no established mechanism. Its development is probably characterized by the interaction between biological, genetic and environmental factors (Oladeji and

\footnotetext{
* Corresponding author at: Maastricht UMC+, Dept. Medicine, p/a De Maastricht Studie, Randwycksingel 35, 6229 EG Maastricht, The Netherlands.

E-mail address: F.E.P.vanDooren@uvt.nl (F.E.P. van Dooren).
}

Gureje, 2013). Apart from the detrimental impact of depression on the quality of life of individuals affected with the disorder and their family members, depression is also related to high societal costs as a consequence of diminished work productivity and increased use of health care (Greenberg et al., 2015). According to the World Health Organization (WHO), depression is the leading cause of disability worldwide, and is a major contributor to the overall global burden of disease as measured by Disability Adjusted Lived Years (WHO, 2015), therefore making the identification of its etiology a research priority. 
Increasing evidence suggests that inflammatory pathways may play a role in the development of depression (Valkanova et al., 2013), with elevated oxidative stress, (Maes et al., 2011; Riemer et al., 2010) and psychosocial stressors (Moylan et al., 2013) as proposed mechanisms. For example, psychosocial stressors, including acute psychological trauma or early exposure to childhood trauma, strongly increase the risk of developing clinical depression and mood symptoms, while impacting neuroimmune circuits (Berk et al., 2013). There is evidence that different types of psychosocial stressors may stimulate the pro-inflammatory cytokine network, including increases in IL-6 and TNF $\alpha$ (Maes et al., 1998), and subsequently could lead to the development of depression. Moreover, previous research has shown that treatment with the antiinflammatory drug infliximab significantly decreased depressive symptoms in patients with increased CRP, but not in depressed patients without raised inflammatory markers (Raison et al., 2013). In addition, a recent meta-analysis based on 14 trials (Kohler et al., 2014) showed that anti-inflammatory treatment, in particular celecoxib, decreased depressive symptoms without increased risks of adverse effects.

Both inflammation and oxidative stress are strongly linked to the development of endothelial dysfunction. Several studies indeed report an association of endothelial dysfunction with depression (Hemingway et al., 2003; Lesperance et al., 2004; van Sloten et al., 2014). However, large scale studies on the interrelation between inflammation and endothelial dysfunction in their association with depression remain scarce, whereas these processes are biologically interrelated and may therefore be interdependent (Stehouwer et al., 2002). In addition, most studies on endothelial dysfunction and depression yielded inconsistent results, some showing significant positive associations between endothelial dysfunction and depression (Sherwood et al., 2005), whereas others showed no association (Do et al., 2010). This is possibly due to the methods used to assess endothelial dysfunction or depression, i.e. only a few studies have used a diagnostic interview, the gold standard to assess depressive disorder.

In view of the above, we aimed to evaluate whether inflammation and endothelial dysfunction, as measured with a wide variety of biomarkers, are positively associated with depressive symptoms and depressive disorder as assessed with a self-report questionnaire and a diagnostic interview, respectively. Furthermore, we aimed to evaluate whether these associations are independent of the possible confounders age, sex, type 2 diabetes, estimated glomerular filtration rate and prior cardiovascular disease. In addition, we also aimed to evaluate the possible role of several life style factors in this association.

\section{Materials and methods}

\subsection{Study population}

In this study, we used data from The Maastricht Study, an observational prospective population-based cohort study. The rationale and methodology have been described previously (Schram et al., 2014). In brief, the study focuses on the etiology, pathophysiology, complications and comorbidities of type 2 diabetes mellitus and is characterized by an extensive phenotyping approach. Extensive assessments of both depressive symptoms and depressive disorder were part of the protocol. Eligible for participation were all individuals aged between 40 and 75 years and living in the southern part of the Netherlands. Participants were recruited through mass media campaigns and from the municipal registries and the regional Diabetes Patient Registry via mailings. Recruitment was stratified according to known type 2 diabetes status, with an oversampling of individuals with type 2 diabetes, for reasons of efficiency. The present report includes cross-sectional data from the first 852 participants, who completed the baseline survey between November 2010 and March 2012. The examinations of each participant were performed within a time window of three months, and all measurements were performed in The Maastricht Study research center using standardized protocols. The study has been approved by the institutional medical ethical committee (NL31329.068.10) and the Netherlands Health Council under the Dutch "Law for Population Studies" (Permit 131088105234-PG). All participants gave written informed consent.

\subsection{Markers of low-grade inflammation (LGI) and endothelial dysfunction (ED)}

Plasma biomarkers of LGI (high sensitivity C-reactive protein (CRP), serum amyloid A (SAA), soluble intercellular adhesion molecule-1 (sICAM-1), interleukin-6 (IL-6), interleukin-8 (IL-8) and tumor necrosis factor alpha (TNF- $\alpha$ )) were measured in EDTA plasma samples with commercially available 4-plex sandwich immunoassay kits (Meso Scale Discovery (MSD), Rockville, MD, US). For this study, the intra- and inter-assay coefficients of variation were $3.0 \%$ and $4.7 \%$ for CRP, $2.6 \%$ and $7.5 \%$ for SAA, $2.5 \%$ and $5.3 \%$ for sICAM-1, $7.2 \%$ and $12.7 \%$ for IL-6, 3.1\% and 5.6\% for IL-8, and $4.3 \%$ and $7.5 \%$ for TNF- $\alpha$, respectively. Of the plasma biomarkers of ED (soluble vascular cell adhesion molecule-1 (sVCAM-1), sICAM-1, soluble E-selectin (sE-selectin) and Von Willebrand factor $(v W F)$ ), sVCAM-1, sICAM-1, and sE-selectin were measured in EDTA plasma samples with commercially available 4-plex sandwich immunoassay kits (Meso Scale Discovery (MSD), Rockville, MD, US). vWf was determined in citrated plasma with sandwich ELISA (Dako, Glostrup, Denmark). Concentrations of vWf were expressed as a percentage of vWf detected in pooled citrated plasma of healthy volunteers. For the present study, the intraand inter-assay coefficients of variation were $3.5 \%$ and $5.9 \%$ for sVCAM-1, $2.5 \%$ and $5.3 \%$ for SICAM-1, $6.4 \%$ and $6.0 \%$ for sEselectin, and $3.2 \%$ and $5.4 \%$ for vWF.

\subsection{Assessment of depression}

Depressive symptoms in the preceding two weeks were assessed by a validated Dutch version of the 9-item Patient Health Questionnaire (PHQ-9) (Kroenke et al., 2001). The PHQ-9 is a selfadministered questionnaire based on the DMS-IV (APA, 1994) criteria for a major depressive disorder. It comprises nine items rated on a four-point scale, ranging from $0=$ "not at all" to $3=$ "nearly every day". Response options are used to calculate a continuous total-score ranging from 0 (no symptoms) to 27 (all symptoms present nearly every day). Depressive disorder was assessed by the Mini-International Neuropsychiatric Interview (MINI) (Sheehan et al., 1998). The MINI is a short diagnostic structured interview, used to assess the presence of current minor or major depressive disorder in the preceding 2 weeks according to the DSM-IV (Diagnostic and Statistical Manual of Mental Disorders, Fourth Edition).

\subsection{Data collection}

Partner status, diabetes duration, smoking behavior, alcohol consumption, physical activity and history of cardiovascular disease (CVD) were assessed by means of a self-report questionnaire (Schram et al., 2014). Fasting venous blood samples were used to assess glucose levels, $\mathrm{HbA}_{1 \mathrm{c}}$ and lipid profile. Medication use was assessed by interview. Office blood pressure was measured three times on the right arm after 10 min of seated rest, the mean of these three measurements was used for analyses.

To determine diabetes status, all participants (except those who use insulin) underwent a standardized 7-point $75 \mathrm{~g}$ oral glucose tolerance test (OGTT) after an overnight fast as previously 
described (Schram et al., 2014). Individuals without type 1 diabetes (T1DM) and on diabetes medication were considered to have T2DM (Schram et al., 2014). Weight, height, waist and hip circumference were measured, subsequently body mass index (BMI) and waist-to-hip ratio were calculated. Glomerular filtration rate (eGFR) was estimated according to the CKD-EPI (Chronic Kidney Disease Epidemiology Collaboration) equation, based on serum creatinine (Levey et al., 2009).

\subsection{Statistical analyses}

All analyses were performed using SPSS version 19 for MSWindows (SPSS, Inc.). Baseline characteristics of individuals with versus without depressive disorder were compared using Independent Samples T-tests, Mann-Whitney $U$ test and Chi-square tests, where appropriate. All variables with a skewed distribution were log-transformed before regression analyses. For reasons of statistical efficiency and to reduce the influence of the biological variability of each measure, a standardized sum score was determined for both LGI and ED, according to predefined clusters of conceptually related biomarkers (de Jager et al., 2006; Yudkin et al., 1999). Before creating the sum scores, variables with a skewed distribution were log-transformed. The standardized sum scores were calculated as follows: for each individual biomarker, a z-score was calculated according to the formula: (individual value - population mean)/population standard deviation. The resulting individual biomarker z-scores were then averaged into an overall standardized sum score for both LGI and ED using the same formula. The LGI sum score consisted of the biomarkers CRP, SAA, sICAM-1, IL-6, IL-8 and TNF- $\alpha$; and the ED sum score consisted of the biomarkers sVCAM-1, sICAM-1, sE-selectin and vWF. sICAM-1 was included in both sum scores, as it is expressed by both monocytes and the endothelium (Schram and Stehouwer, 2005). To check whether this influenced the results, we also calculated the overall sum scores for inflammation and endothelial dysfunction without sICAM-1.

Linear regression analyses were used to assess the associations between individual biomarkers and sum scores of inflammation and endothelial dysfunction with the level of depressive symptoms. Logistic regression analyses were used to assess the associations between individual biomarkers and sum scores of inflammation and endothelial dysfunction with depressive disorder. Due to the relatively low number of depression cases a maximum of 6 confounding variables were included in the analyses. Analyses were adjusted for covariates in a three way approach: model 1 was the crude model, in model 2 demographic variables age and sex were incorporated, and model 3 additionally included the clinical variables T2DM, eGFR and history of CVD. To evaluate the effects of lifestyle factors on the association of LGI and ED with

Table 1

General characteristics of The Maastricht Study participants.

\begin{tabular}{|c|c|c|c|c|}
\hline & \multirow[t]{2}{*}{ Total population $(\mathrm{n}=852)$} & \multicolumn{2}{|c|}{ Depressive disorder ( $\mathrm{n}=852$; MINI) } & \multirow[t]{2}{*}{ p-Value } \\
\hline & & No $(n=797)$ & Yes $(n=55)$ & \\
\hline Male sex (n) & $55 \%(467)$ & $55 \%(438)$ & $53 \%(29)$ & $0.748^{\mathrm{a}}$ \\
\hline Age, years & $59.8 \pm 8.5$ & $59.8 \pm 8.5$ & $59.0 \pm 8.9$ & $0.463^{\mathrm{b}}$ \\
\hline Having a partner $(\mathrm{n})$ & $85 \%(715)$ & $86 \%(673)$ & $76 \%(42)$ & $0.063^{\mathrm{a}}$ \\
\hline Type 2 diabetes $(\mathrm{n})$ & $29 \%(251)$ & $29 \%(229)$ & $40 \%(22)$ & $0.076^{\mathrm{a}}$ \\
\hline Diabetes duration, years & $8.4 \pm 6.9$ & $8.1 \pm 6.9$ & $10.4 \pm 6.7$ & $0.176^{\mathrm{b}}$ \\
\hline HbA1c, \% & $6.0 \pm 0.8$ & $6.0 \pm 0.8$ & $6.4 \pm 1.2$ & $0.042^{c}$ \\
\hline Fasting glucose level, $\mathrm{mmol} / \mathrm{L}$ & $6.1 \pm 1.5$ & $6.1 \pm 1.4$ & $6.6 \pm 2.6$ & $0.140^{c}$ \\
\hline Smoking; never/former/current (\%) & $31 \% / 53 \% / 16 \%$ & $32 \% / 53 \% / 15 \%$ & $19 \% / 51 \% / 30 \%$ & $\mathbf{0 . 0 0 9}^{\mathrm{a}}$ \\
\hline Alcohol consumption; no/low/high (\%) & $17 \% / 53 \% / 30 \%$ & $17 \% / 53 \% / 30 \%$ & $24 \% / 49 \% / 27 \%$ & $0.511^{\mathrm{a}}$ \\
\hline BMI, $\mathrm{kg} / \mathrm{m}^{2}$ & $27.4 \pm 4.5$ & $27.3 \pm 4.5$ & $28.2 \pm 5.1$ & $0.184^{\mathrm{b}}$ \\
\hline Waist circumference, $\mathrm{cm}$ & $97.2 \pm 13.6$ & $97.0 \pm 13.4$ & $99.6 \pm 15.8$ & $0.175^{\mathrm{b}}$ \\
\hline Waist-to-hip ratio & $0.95 \pm 0.09$ & $0.95 \pm 0.09$ & $0.96 \pm 0.10$ & $0.266^{\mathrm{b}}$ \\
\hline Physical activity & $14.3 \pm 8.0$ & $14.5 \pm 8.2$ & $11.5 \pm 4.8)$ & $\mathbf{0 . 0 0 1} 1^{\mathrm{b}}$ \\
\hline Systolic blood pressure, mmHg & $137.4 \pm 19.0$ & $137.1 \pm 18.9$ & $141.0 \pm 20.4$ & $0.141^{\mathrm{b}}$ \\
\hline Diastolic blood pressure, $\mathrm{mmHg}$ & $76.7 \pm 10.3$ & $76.7 \pm 10.2$ & $77.5 \pm 12.3$ & $0.544^{\mathrm{b}}$ \\
\hline Anti-hypertensive medication & $40 \%(342)$ & $40 \%(316)$ & $47 \%(26)$ & $0.265^{\mathrm{a}}$ \\
\hline Total cholesterol, $\mathrm{mmol} / \mathrm{L}$ & $5.2 \pm 1.2$ & $5.2 \pm 1.2$ & $5.2 \pm 1.2$ & $0.991^{\mathrm{b}}$ \\
\hline Total-to-HDL cholesterol ratio & $4.5 \pm 8.6$ & $4.5 \pm 8.8$ & $4.5 \pm 1.5$ & $0.970^{\mathrm{b}}$ \\
\hline Lipid-modifying medication & $37 \%(315)$ & $37 \%(292)$ & $42 \%(23)$ & $0.441^{\mathrm{a}}$ \\
\hline History of CVD & $18 \%(147)$ & $18 \%(139)$ & $15 \%(8)$ & $0.610^{\mathrm{a}}$ \\
\hline Estimated GFR, $\mathrm{ml} / \mathrm{min} / 1.73 \mathrm{~m}^{2}$ & $84.7 \pm 14.6$ & $84.7 \pm 14.7$ & $84.7 \pm 13.6$ & $0.998^{\mathrm{b}}$ \\
\hline $\begin{array}{l}\text { C-reactive protein }(\mu \mathrm{g} / \mathrm{ml}) \\
\quad \text { Median (interquartile range) }\end{array}$ & $1.19 \pm 2.2$ & $1.15 \pm 2.1$ & $2.07 \pm 2.8$ & $<0.001^{d}$ \\
\hline $\begin{array}{l}\text { Serum amyloid } \mathrm{A}(\mu \mathrm{g} / \mathrm{ml}) \\
\quad \text { Median (interquartile range) }\end{array}$ & $2.77 \pm 3.4$ & $2.74 \pm 3.2$ & $4.28 \pm 6.5$ & $\mathbf{0 . 0 0 5} 5^{d}$ \\
\hline sICAM-1 (ng/ml) & $258.5 \pm 68.1$ & $256.7 \pm 67.4$ & $284.9 \pm 71.9$ & $0.003^{\mathrm{b}}$ \\
\hline $\begin{array}{l}\text { Interleukin-6 (pg/ml) } \\
\quad \text { Median (interquartile range) }\end{array}$ & $1.43 \pm 1.2$ & $1.42 \pm 1.14$ & $1.68 \pm 1.36$ & $0.078^{\mathrm{d}}$ \\
\hline $\begin{array}{l}\text { Interleukin-8 (pg/ml) } \\
\quad \text { Median (interquartile range) }\end{array}$ & $3.76 \pm 1.7$ & $3.75 \pm 1.7$ & $4.02 \pm 2.4$ & $0.309^{\mathrm{d}}$ \\
\hline $\begin{array}{l}\text { Tumor necrosis factor alpha }(\mathrm{pg} / \mathrm{ml} \text { ) } \\
\text { Median (interquartile range) }\end{array}$ & $2.53 \pm 1.0$ & $2.52 \pm 1.0$ & $2.68 \pm 1.3$ & $0.058^{\mathrm{d}}$ \\
\hline sVCAM-1 (ng/ml) & $404.1 \pm 101.0$ & $402.4 \pm 101.0$ & $428.5 \pm 99.3$ & $0.064^{\mathrm{b}}$ \\
\hline $\mathrm{sE}-$ Selectin $(\mathrm{ng} / \mathrm{ml})$ & $13.4 \pm 7.6$ & $13.2 \pm 7.4$ & $16.5 \pm 10.3$ & $\mathbf{0 . 0 0 2} 2^{\mathrm{b}}$ \\
\hline Von Willebrand factor (\%) & $134.9 \pm 47.6$ & $134.3 \pm 47.8$ & $143.1 \pm 44.8$ & $0.187^{\mathrm{b}}$ \\
\hline Total score on PHQ-9 & $2.7 \pm 3.6$ & $2.2 \pm 2.6$ & $10.6 \pm 6.8$ & $<\mathbf{0 . 0 0 1}$ \\
\hline
\end{tabular}

Data are presented as mean \pm standard deviation unless otherwise indicated.

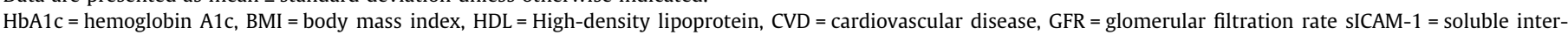
cellular adhesion molecule-1, sVCAM-1 = soluble vascular cell adhesion molecule-1, PHQ-9 = Patient Health Questionnaire 9 items.

a Chi-square.

b Independent Samples T-Test.

c T-Test, equal variances not assumed.

d Mann Whitney-U. 
depression, associations were additionally adjusted for smoking, alcohol use and BMI in separate models. A sensitivity analysis was performed for the lifestyle variable physical activity, due to the large number of missing values on this variable. A P-value $<0.05$ was considered to indicate statistical significance in twosided tests.

The Maastricht Study is characterized by oversampling of T2DM. Therefore, a sensitivity analysis was performed to examine whether the associations between LGI, ED and measures of depression differed between individuals with and without T2DM. For interaction terms a P-value of $<0.10$ was considered to indicate statistically significant interaction.

\section{Results}

\subsection{General characteristics}

Table 1 shows the general characteristics of the study population, consisting of 852 participants (55\% men, mean age 60 years), according to diagnosis of depressive disorder. Data on biomarkers of ED were available in 831 individuals, data on biomarkers of LGI were available in 842 individuals. Missing data on biomarkers were caused by difficulties in blood withdrawal. Data on depression for the MINI interview were available in 852 individuals, PHQ-9 scores in 757. Missing data on depression scores were mainly due to not completing the questionnaires or rejecting the interview. In total, $6.5 \%(n=55)$ of the participants had a minor or major depressive disorder. These individuals had higher $\mathrm{HbA}_{1 \mathrm{c}}$ levels, were more likely to smoke, less likely to be physically active and had higher levels of CRP, SAA, sICAM-1 and sE-selectin.

\subsection{Association of LGI with depression}

Table 2 shows crude associations of higher CRP, TNF- $\alpha$, SAA and sICAM-1 with depressive symptoms (regression coefficients ( $\beta \mathrm{s}$ ) and $95 \%$ confidence interval [95\%CI]; 0.38 [0.12; 0.64], 0.33 [0.06; 0.59 ], 0.31 [0.05; 0.58] and 0.40 [0.12; 0.68], respectively, in separate models), and depressive disorder (odds ratios (ORs) and 95\% CI; 1.64 [1.25; 2.15], [1.34 1.03; 1.75], 1.42 [1.11; 1.82] and 1.35 $[1.10 ; 1.64]$, respectively). IL-6 and IL-8 were not associated with depressive symptoms and depressive disorder. Furthermore, the sum score of LGI was statistically significantly associated with depressive symptoms ( $\beta 0.46[0.19 ; 0.72])$ and depressive disorder (OR 1.51 [1.19; 1.91]).

Table 3 shows an association of the sum score of LGI with depressive symptoms and depressive disorder after adjustment for age, sex, T2DM, eGFR and prior CVD ( $\beta 0.49$ [0.21; 0.77] and OR $1.54[1.18 ; 2.02]$ respectively). Additional adjustment for the

Table 2

Univariate associations of individual biomarkers and the sum score of low-grade inflammation with measures of depression.

\begin{tabular}{|c|c|c|c|c|c|c|}
\hline \multirow{2}{*}{$\begin{array}{l}\text { Independent } \\
\text { variable }\end{array}$} & \multicolumn{3}{|c|}{ Depressive symptoms } & \multicolumn{3}{|c|}{ Depressive disorder $(n=55)$} \\
\hline & B & $95 \% \mathrm{CI}$ & p-Value & OR & $95 \% \mathrm{CI}$ & p-Value \\
\hline $\mathrm{CRP}^{\mathrm{a}}$ & 0.38 & $0.12 ; 0.64$ & 0.004 & 1.64 & $1.25 ; 2.15$ & $<0.001$ \\
\hline TNF- $\alpha^{a}$ & 0.33 & $0.06 ; 0.59$ & 0.017 & 1.34 & $1.03 ; 1.75$ & 0.032 \\
\hline $\mathrm{SAA}^{\mathrm{a}}$ & 0.31 & $0.05 ; 0.58$ & 0.021 & 1.42 & $1.11 ; 1.82$ & 0.005 \\
\hline sICAM-1 & 0.40 & $0.12 ; 0.68$ & 0.006 & 1.35 & $1.10 ; 1.65$ & 0.004 \\
\hline IL-6 $6^{\mathrm{a}}$ & 0.18 & $-0.08 ; 0.44$ & 0.170 & 1.13 & $0.90 ; 1.43$ & 0.290 \\
\hline IL-8 $8^{\mathrm{a}}$ & 0.18 & $-0.09 ; 0.44$ & 0.196 & 1.13 & $0.90 ; 1.44$ & 0.297 \\
\hline LGI sum score & 0.46 & $0.19 ; 0.72$ & 0.001 & 1.51 & $1.19 ; 1.91$ & 0.001 \\
\hline
\end{tabular}

Independent variables reflect Z-scores.

$\mathrm{CRP}=\mathrm{C}$-reactive protein, TNF- $\alpha=$ tumor necrosis factor alpha, $\mathrm{SAA}=$ serum amyloid A, sICAM-1 = soluble intercellular adhesion molecule-1, IL-6 = interleukin-6, IL8 = interleukin-8, LGI = low-grade inflammation.

a Variables were log-transformed prior to standardization. lifestyle factors smoking, alcohol, and BMI did not materially alter the associations with depressive symptoms or depressive disorder.

\subsection{Association of ED with depression}

Table 4 shows crude associations of higher sICAM- 1 and sESelectin levels with depressive symptoms ( $\beta 0.40[0.12 ; 0.68]$ and $\beta 0.26[0.00 ; 0.53]$ respectively) and depressive disorder (OR 1.35 $[1.10 ; 1.65]$ and OR $1.36[1.11 ; 1.66]$ respectively), while sVCAM1 and vWF were not associated with depressive symptoms or depressive disorder. Additionally, the ED sum score was statistically significantly associated with depressive symptoms ( $\beta 0.35$ $[0.08 ; 0.63]$ ) and depressive disorder (OR 1.40 [1.14; 1.73]).

Table 5 shows an association of the sum score of ED with depressive symptoms after adjustment for age and sex ( $\beta 0.52$ $[0.24 ; 0.80])$, however, after additional adjustments the association estimate weakened, and became non-significant. Furthermore, a statistically significant association was found for the sum score of ED with depressive disorder after adjustment for age, sex, T2DM, eGFR and prior CVD (OR 1.40 [1.10; 1.77]). Additional adjustment for the lifestyle factors smoking, alcohol and BMI did not materially alter the association with depressive disorder.

\subsection{Sensitivity analyses}

Because the number of missing on the variable "physical activity" was 136 for the total sample, and 19 for depressed participants, we adjusted for this lifestyle factor in a sensitivity analysis to sustain power in the main analyses. These additional adjustments did not materially alter the associations of LGI with depressive symptoms or depressive disorder, nor the association of ED with depressive symptoms (data not shown). However, the association of ED with depressive disorder weakened after adjustment for physical activity, and became non-significant (OR 1.19, 95\%CI $0.87 ; 1.63, p=0.273$ ), probably due to the reduced statistical power of that particular analysis.

To determine whether the associations between LGI, ED and measures of depression were different across T2DM status, an interaction term was added to the regression models. No significant interactions were observed (data not shown). In addition, we performed logistic regression analyses for minor and major depression separately to see whether there were different effect sizes for both measures. Although the number of cases was low, the effect sizes of the observed associations were similar (data not shown).

Furthermore, overall sum scores for LGI and ED were calculated without sICAM-1, to check whether this influenced the results. Excluding s-ICAM-1 from the overall sum scores did not change the results (data not shown).

\section{Discussion}

In this study we found that both low grade inflammation and endothelial dysfunction were associated with depressive disorder, independent of age, sex, type 2 diabetes status, estimated glomerular filtration rate, prior cardiovascular disease and lifestyle factors smoking, alcohol consumption and body mass index. The association of low grade inflammation with depressive symptoms was independent of lifestyle factors, while the association of endothelial dysfunction attenuated by adjustment for smoking, alcohol use and body mass index.

\subsection{LGI and depression}

We found that higher levels of individual biomarkers CRP and TNF- $\alpha$ were significantly associated with depressive symptoms 
Table 3

Associations of the sum score of low-grade inflammation with depressive symptoms and depressive disorder.

\begin{tabular}{|c|c|c|c|c|c|c|c|c|}
\hline \multirow[t]{2}{*}{ Independent variable } & \multicolumn{3}{|c|}{ Depressive symptoms } & \multirow[t]{2}{*}{$\mathrm{N}$ included in analysis } & \multicolumn{3}{|c|}{ Depressive disorder } & \multirow{2}{*}{$\begin{array}{l}\mathrm{N} \text { included in analysis } \\
\text { No depression/depression }\end{array}$} \\
\hline & $\mathrm{B}$ & $95 \% \mathrm{CI}$ & p-Value & & OR & $95 \% \mathrm{CI}$ & p-Value & \\
\hline Model 1: crude & 0.46 & $0.19 ; 0.72$ & 0.001 & 731 & 1.51 & $1.19 ; 1.91$ & 0.001 & $778 / 55$ \\
\hline Model 2: adjusted for age, sex & 0.66 & $0.38 ; 0.93$ & $<0.001$ & 731 & 1.61 & $1.26 ; 2.06$ & $<0.001$ & $778 / 55$ \\
\hline Model 3: model $2+$ T2DM, eGFR, prior CVD & 0.49 & $0.21 ; 0.77$ & 0.001 & 709 & 1.54 & $1.18 ; 2.02$ & 0.001 & $744 / 52$ \\
\hline Model 4: model $3+$ smoking & 0.37 & $0.09 ; 0.65$ & 0.009 & 706 & 1.43 & $1.09 ; 1.88$ & 0.011 & $742 / 51$ \\
\hline Model 5: model $3+$ alcohol consumption & 0.47 & $0.19 ; 0.76$ & 0.001 & 704 & 1.54 & $1.17 ; 2.03$ & 0.002 & $740 / 50$ \\
\hline Model 6: model $3+$ body mass index & 0.32 & $0.01 ; 0.62$ & 0.042 & 708 & 1.56 & $1.17 ; 2.08$ & 0.002 & $743 / 52$ \\
\hline
\end{tabular}

Independent variables reflect Z-scores.

T2DM = type 2 diabetes, eGFR = estimated glomerular filtration rate, CVD = cardiovascular disease.

Table 4

Univariate associations of individual biomarkers and the sum score of endothelial dysfunction with measures of depression.

\begin{tabular}{|c|c|c|c|c|c|c|}
\hline \multirow{2}{*}{$\begin{array}{l}\text { Independent } \\
\text { variable }\end{array}$} & \multicolumn{3}{|c|}{ Depressive symptoms } & \multicolumn{3}{|c|}{ Depressive disorder $(n=55)$} \\
\hline & B & $95 \% \mathrm{CI}$ & p-Value & OR & $95 \% \mathrm{CI}$ & p-Value \\
\hline sVCAM-1 & 0.23 & $-0.03 ; 0.50$ & 0.083 & 1.25 & $0.99 ; 1.58$ & 0.065 \\
\hline sICAM-1 & 0.40 & $0.12 ; 0.68$ & 0.006 & 1.35 & $1.10 ; 1.65$ & 0.004 \\
\hline sE-Selectin & 0.26 & $0.00 ; 0.53$ & 0.050 & 1.36 & $1.11 ; 1.66$ & 0.003 \\
\hline vWF & 0.10 & $-0.17 ; 0.36$ & 0.472 & 1.19 & $0.92 ; 1.53$ & 0.188 \\
\hline ED sum score & 0.35 & $0.08 ; 0.63$ & 0.012 & 1.40 & $1.14 ; 1.73$ & 0.001 \\
\hline
\end{tabular}

Independent variables reflect Z-scores.

sVCAM-1 = soluble vascular cell adhesion molecule- 1 , sICAM-1 = soluble intercellular adhesion molecule-1, $\mathrm{vWF}=\mathrm{Von}$ Willebrand factor, $\mathrm{ED}=$ endothelial dysfunction.

and depressive disorder, while this was also the case for markers SAA and sICAM-1. Accordingly, higher levels of the sum score of LGI were significantly associated with depressive symptoms and depressive disorder, independent of possible covariates.

Various hypotheses have been proposed as an explanation for the association of inflammation with depression. First, inflammation could induces sickness behavior, which is closely related to or may induce symptoms of depression. A previous review by Dantzer et al. (2008) concluded that pro-inflammatory cytokines are able to cause depressive disorder, via immune-to-brain communication in which pro-inflammatory cytokines cause feelings of depression via different pathways. The first pathway proposed by Dantzer et al. is the neural pathway in which locally produced cytokines activate primary afferent nerves in the brain during infection (Romeo et al., 2001). The second pathway is the humoral pathway, in which Toll-like receptors outside the blood-brain barrier produce pro-inflammatory cytokines which enter the brain via fluid diffusion (Vitkovic et al., 2000). A third pathway comprises cytokine transporters at the blood-brain barrier; proinflammatory cytokines overflowing in the systemic circulation can gain access to the brain through these transport systems (Banks, 2006). A fourth pathway involves IL-1 receptors that are located on endothelial cells of brain venules. Activation of these
IL-1 receptors by circulating cytokines results in the local production of prostaglandins (Schiltz and Sawchenko, 2002). Engagement of these immune-to-brain communication pathways ultimately leads to the production of pro-inflammatory cytokines by microglial cells in the brain, which consequently can induce symptoms of depression (Dantzer et al., 2008).

Another potential pathway for the association of inflammation with depression refers to the vascular depression hypothesis, which postulates that vascular damage in the brain predisposes to depressive symptoms via damage to deep and frontal brain structures that are involved in mood regulation (Alexopoulos et al., 1997). As immune dysregulation is critically involved in vascular disease (Willerson and Ridker, 2004), and promotes endothelial dysfunction, this vascular damage could be the result of increased levels of inflammation. In addition, there is evidence suggesting that inflammation can cause HPA-axis hyperactivity by disturbing the negative feedback inhibition of circulating corticosteroids on the HPA-axis (Schiepers et al., 2005), which in turn is known to be associated with depression, and causes hypotrophy in the hypothalamus, hippocampus and pre-frontal cortex (Zunszain et al., 2011).

However, when studying the association between inflammation and depression, the effects of (adverse) health behaviors/lifestyle factors should also be taken into account. Several lifestyle factors are known to relate to depression such as smoking (Luger et al., 2014), alcohol intake (Boden and Fergusson, 2011), and obesity (Luppino et al., 2010), and they also have an influence on lowgrade inflammation and endothelial dysfunction. For instance, cigarette smoking is known to promote inflammation (McEvoy et al., 2015), possibly via the production of reactive oxygen species (ROS). Observational studies indicate that moderate drinkers have lower levels of markers of inflammation, especially CRP, while nondrinkers and heavy drinkers have higher CRP concentrations (Imhof et al., 2001). Obesity has also been linked to inflammation, as in people with obesity the levels of CRP, IL- 6 and TNF- $\alpha$ have been demonstrated to be higher compared to people with a normal weight, probably through the production of inflammatory markers by adipocytes (Park et al., 2005). It could therefore be suggested that lifestyle factors could play an important confounding role in

Table 5

Associations of the sum score of endothelial dysfunction with depressive symptoms and depressive disorder.

\begin{tabular}{|c|c|c|c|c|c|c|c|c|}
\hline \multirow[t]{2}{*}{ Independent variable } & \multicolumn{3}{|c|}{ Depressive symptoms } & \multirow[t]{2}{*}{$\mathrm{N}$ included in analysis } & \multicolumn{3}{|c|}{ Depressive disorder } & \multirow{2}{*}{$\begin{array}{l}\mathrm{N} \text { included in analysis } \\
\text { No depression/depression }\end{array}$} \\
\hline & $\mathrm{B}$ & $95 \% \mathrm{CI}$ & p-Value & & OR & $95 \% \mathrm{CI}$ & p-Value & \\
\hline Model 1: crude & 0.35 & $0.08 ; 0.63$ & 0.012 & 720 & 1.40 & $1.14 ; 1.73$ & 0.001 & $767 / 55$ \\
\hline Model 2: adjusted for age, sex & 0.52 & $0.24 ; 0.80$ & $<0.001$ & 720 & 1.47 & $1.18 ; 1.82$ & $<0.001$ & $767 / 55$ \\
\hline Model 3: model $2+$ T2DM, eGFR, prior CVD & 0.28 & $-0.01 ; 0.57$ & 0.060 & 698 & 1.40 & $1.10 ; 1.77$ & 0.006 & $733 / 52$ \\
\hline Model 4: model $3+$ smoking & 0.20 & $-0.09 ; 0.48$ & 0.173 & 695 & 1.34 & $1.05 ; 1.70$ & 0.020 & $731 / 51$ \\
\hline Model 5: model $3+$ alcohol consumption & 0.24 & $-0.06 ; 0.53$ & 0.116 & 693 & 1.37 & $1.07 ; 1.75$ & 0.013 & $729 / 50$ \\
\hline Model 6: model $3+$ body mass index & 0.12 & $-0.18 ; 0.43$ & 0.426 & 697 & 1.39 & $1.08 ; 1.79$ & 0.010 & $732 / 52$ \\
\hline
\end{tabular}


the association between inflammation and depression. Nevertheless, in our study inflammation remained significantly associated with depressive disorder and depressive symptoms after adjustment for smoking, alcohol use and body mass index.

\subsection{ED and depression}

Our results showed that higher levels of SICAM-1 and SEselectin were significantly associated with a higher levels of depressive symptoms and greater risk of depressive disorder. Higher levels of the sum score of ED were associated with higher levels of depressive symptoms, however, after adjustment for clinical and lifestyle variables this association became non-significant. In addition, higher levels of the sum score of ED was significantly associated with depressive disorder, independent of possible covariates.

A growing body of literature has linked endothelial dysfunction with depression (Hemingway et al., 2003; Lesperance et al., 2004). The association seems to be graded and linear, such that even minor increases in depressive symptoms are joined with decreased endothelial function (Lavoie et al., 2010; Tomfohr et al., 2008). For example, a meta-analyses of twelve studies (Cooper et al., 2011) showed an association between diminished flow mediated vasodilation (FMD), a functional marker of endothelial dysfunction, and depression. Nonetheless, the question can be raised whether biomarkers of ED and FMD represent the same phenomenon. However, a recent study of our group (van Sloten et al., 2014) used both plasma biomarkers and FMD to measure ED, and showed an independent association of ED with depressive symptoms, confirming our results in a different population. Nevertheless, this study (van Sloten et al., 2013) used a self-report questionnaire for the assessment of depression whereas we additionally used a diagnostic interview, which is the gold standard for the assessment of depression.

The underlying mechanisms linking concurrent depression and endothelial function in prospective studies remain unclear; however, several biological mechanisms have been proposed. For example, depressive mood was associated with dysregulation of the autonomic nervous system and HPA-axis (Goldston and Baillie, 2008), both of which are associated with ED (Harris and Matthews, 2004). It has also been suggested that ED may lead to depression via the development of cardiovascular disease, as ED is a key factor in its pathophysiology (Aird, 2007), and depression is common in people with CVD (Belmaker and Agam, 2008). Nonetheless, when we adjusted for prior CVD and T2DM, a CVD risk factor, the association between ED and depressive disorder remained significant, suggesting that this association is independent of CVD.

Lifestyle factors may also play an important confounding role in the association between ED and depression. All lifestyle factors implemented in our model are known to be associated with both depression (Boden and Fergusson, 2011; Luger et al., 2014; Luppino et al., 2010) and ED. For instance, cigarette smoking has long been known to produce reactive oxygen species (ROS) (Church and Pryor, 1985), which damage the endothelium, thereby causing a reduction in nitric oxide bioavailability and, thus endothelial dysfunction (Kiowski et al., 1994). In contrast, moderate alcohol consumption was found to be associated with improved endothelial function (Teragawa et al., 2002), whereas obesity has been associated with deteriorating endothelial function (Iantorno et al., 2014). However, the association of ED with depressive disorder remained significant after adjustment for lifestyle variables. The association of ED with depressive symptoms attenuated after adjustment for type 2 diabetes, kidney function, prior CVD, and even more after adjusting for smoking, alcohol use and BMI. Therefore, these lifestyle factors can only partly explain the association of ED with depressive symptoms.

As expected, the association of both LGI and ED with depression appeared to be stronger for depressive disorder than for depressive symptoms. This is in accordance with a meta-analysis of Howren et al. (2009), which demonstrated stronger effects between plasma biomarkers and depression for studies using diagnostic interviews as compared self-report questionnaires. Together with the fact that our results were adjusted for possible confounding or mediating factors, our results seem to suggest a true relationship of inflammation and ED with clinically relevant depression.

A limitation of this study is its cross-sectional design. Therefore, we cannot draw any conclusions regarding the causality of the association, as inflammation and endothelial dysfunction could both be a cause or a result of having depression. Another limitation is the loss of power in statistical analyses, due to missing values. Moreover, we do not have any data on the use of antidepressants or other antidepressant treatment available yet, which could potentially have influenced the results. Strengths of our study include the use of both a diagnostic interview and self-report to assess depression, and the wide range of biomarkers that we used to measure inflammation and endothelial dysfunction. All the LGI markers (CRP, SAA, sICAM-1, IL-6, IL-8 and TNF- $\alpha$ ) are involved in the inflammatory process (Ross, 1999) and all the markers of ED (sVCAM-1, sICAM-1, sE-selectin and vWF) are known to be synthesized by endothelial cells (Schram and Stehouwer, 2005; Vischer, 2006). Therefore, it is valid to assume that higher circulating concentrations of these markers reflect more inflammatory activity or dysfunction of the endothelium, respectively.

\section{Conclusions}

Low grade inflammation and endothelial dysfunction were positively associated with depressive disorder, and levels of depressive symptoms. Except for the association between endothelial dysfunction and depressive symptoms, these associations were independent of clinical and lifestyle variables. These results suggest that low grade inflammation and endothelial dysfunction are associated with depression, and that lifestyle factors can only partly explain these associations.

\section{Financial disclosures}

The authors declare that they have no conflicts of interest.

\section{Acknowledgments}

The Maastricht Study was supported by the European Regional Development Fund via OP-Zuid, the Province of Limburg, the Dutch Ministry of Economic Affairs (grant 310.041), Stichting De Weijerhorst (Maastricht, the Netherlands), the Pearl String Initiative Diabetes (Amsterdam, the Netherlands), the Cardiovascular Center (CVC, Maastricht, the Netherlands), School for Mental Health and Neuroscience (MHeNS, Maastricht, The Netherlands), Cardiovascular Research Institute Maastricht (CARIM, Maastricht, the Netherlands), School for Public Health and Primary Care (CAPHRI, Maastricht, the Netherlands), School for Nutrition, Toxicology and Metabolism (NUTRIM, Maastricht, the Netherlands), Stichting Annadal (Maastricht, the Netherlands), Health Foundation Limburg (Maastricht, the Netherlands) and by unrestricted grants from Janssen-Cilag B.V. (Tilburg, the Netherlands), Novo Nordisk Farma B.V. (Alphen aan den Rijn, the Netherlands) and Sanofi-Aventis Netherlands B.V. (Gouda, the Netherlands). 


\section{References}

Aird, W.C., 2007. Phenotypic heterogeneity of the endothelium. I. Structure, function, and mechanisms. Circ. Res. 100, 158-173.

Alexopoulos, G.S., Meyers, B.S., Young, R.C., Campbell, S., Silbersweig, D., Charlson, M., 1997. 'Vascular depression' hypothesis. Arch. Gen. Psychiatry 54, 915-922.

APA, 1994. Diagnostic and Statistical Manual of Mental Disorders, fourth ed. American Psychiatric Association, Washington, DC.

Banks, W.A., 2006. The blood-brain barrier in psychoneuroimmunology. Neurol. Clin. 24, 413-419.

Belmaker, R.H., Agam, G., 2008. Major depressive disorder. N. Engl. J. Med. 358, 5568.

Berk, M., Williams, L.J., Jacka, F.N., O’Neil, A., Pasco, J.A., Moylan, S., Allen, N.B., Stuart, A.L., Hayley, A.C., Byrne, M.L., Maes, M., 2013. So depression is an inflammatory disease, but where does the inflammation come from? BMC Med. $11,200$.

Boden, J.M., Fergusson, D.M., 2011. Alcohol and depression. Addiction 106, 906-914.

Church, D.F., Pryor, W.A., 1985. Free-radical chemistry of cigarette smoke and its toxicological implications. Environ. Health Perspect. 64, 111-126.

Cooper, D.C., Tomfohr, L.M., Milic, M.S., Natarajan, L., Bardwell, W.A., Ziegler, M.G. Dimsdale, J.E., 2011. Depressed mood and flow-mediated dilation: a systematic review and meta-analysis. Psychosom. Med. 73, 360-369.

Dantzer, R., O'Connor, J.C., Freund, G.G., Johnson, R.W., Kelley, K.W., 2008. From inflammation to sickness and depression: when the immune system subjugates the brain. Nat. Rev. Neurosci. 9, 46-56.

de Jager, J., Dekker, J.M., Kooy, A., Kostense, P.J., Nijpels, G., Heine, R.J., Bouter, L.M., Stehouwer, C.D., 2006. Endothelial dysfunction and low-grade inflammation explain much of the excess cardiovascular mortality in individuals with type 2 diabetes: the Hoorn Study. Arterioscler. Thromb. Vasc. Biol. 26, 1086-1093.

Do, D.P., Dowd, J.B., Ranjit, N., House, J.S., Kaplan, G.A., 2010. Hopelessness, depression, and early markers of endothelial dysfunction in U.S. adults. Psychosom. Med. 72, 613-619.

Goldston, K., Baillie, A.J., 2008. Depression and coronary heart disease: a review of the epidemiological evidence, explanatory mechanisms and management approaches. Clin. Psychol. Rev. 28, 288-306.

Greenberg, P.E., Fournier, A.A., Sisitsky, T., Pike, C.T., Kessler, R.C., 2015. The economic burden of adults with major depressive disorder in the United States (2005 and 2010). J. Clin. Psychiatry 76, 155-162.

Harris, K.F., Matthews, K.A., 2004. Interactions between autonomic nervous system activity and endothelial function: a model for the development of cardiovascular disease. Psychosom. Med. 66, 153-164.

Hemingway, H., Shipley, M., Mullen, M.J., Kumari, M., Brunner, E., Taylor, M., Donald, A.E., Deanfield, J.E., Marmot, M., 2003. Social and psychosocial influences on inflammatory markers and vascular function in civil servants (the Whitehall II study). Am. J. Cardiol. 92, 984-987.

Howren, M.B., Lamkin, D.M., Suls, J., 2009. Associations of depression with Creactive protein, IL-1, and IL-6: a meta-analysis. Psychosom. Med. 71, 171-186.

Iantorno, M., Campia, U., Di Daniele, N., Nistico, S., Forleo, G.B., Cardillo, C., Tesauro, M., 2014. Gut hormones and endothelial dysfunction in patients with obesity and diabetes. Int. J. Immunopathol. Pharmacol. 27, 433-436.

Imhof, A., Froehlich, M., Brenner, H., Boeing, H., Pepys, M.B., Koenig, W., 2001. Effect of alcohol consumption on systemic markers of inflammation. Lancet 357, 763 767.

Kiowski, W., Linder, L., Stoschitzky, K., Pfisterer, M., Burckhardt, D., Burkart, F., Buhler, F.R., 1994. Diminished vascular response to inhibition of endotheliumderived nitric oxide and enhanced vasoconstriction to exogenously administered endothelin-1 in clinically healthy smokers. Circulation 90, 27-34.

Kohler, O., Benros, M.E., Nordentoft, M., Farkouh, M.E., Iyengar, R.L., Mors, O., Krogh, J., 2014. Effect of anti-inflammatory treatment on depression, depressive symptoms, and adverse effects: a systematic review and meta-analysis of randomized clinical trials. JAMA Psychiatry 71, 1381-1391.

Kroenke, K., Spitzer, R.L., Williams, J.B., 2001. The PHQ-9: validity of a brief depression severity measure. J. Gen. Intern. Med. 16, 606-613.

Lavoie, K.L., Pelletier, R., Arsenault, A., Dupuis, J., Bacon, S.L., 2010. Association between clinical depression and endothelial function measured by forearm hyperemic reactivity. Psychosom. Med. 72, 20-26.

Lesperance, F., Frasure-Smith, N., Theroux, P., Irwin, M., 2004. The association between major depression and levels of soluble intercellular adhesion molecule 1 , interleukin-6, and C-reactive protein in patients with recent acute coronary syndromes. Am. J. Psychiatry 161, 271-277.

Levey, A.S., Stevens, L.A., Schmid, C.H., Zhang, Y.L., Castro 3rd, A.F., Feldman, H.I., Kusek, J.W., Eggers, P., Van Lente, F., Greene, T., Coresh, J., Ckd, E.P.I., 2009. A new equation to estimate glomerular filtration rate. Ann. Intern. Med. 150, 604-612.

Luger, T.M., Suls, J., Vander Weg, M.W., 2014. How robust is the association between smoking and depression in adults? A meta-analysis using linear mixed-effects models. Addict. Behav. 39, 1418-1429.

Luppino, F.S., de Wit, L.M., Bouvy, P.F., Stijnen, T., Cuijpers, P., Penninx, B.W., Zitman, F.G., 2010. Overweight, obesity, and depression: a systematic review and metaanalysis of longitudinal studies. Arch. Gen. Psychiatry 67, 220-229.

Maes, M., Galecki, P., Chang, Y.S., Berk, M., 2011. A review on the oxidative and nitrosative stress (O\&NS) pathways in major depression and their possible contribution to the (neuro)degenerative processes in that illness. Prog. Neuropsychopharmacol. Biol. Psychiatry 35, 676-692.

Maes, M., Song, C., Lin, A., De Jongh, R., Van Gastel, A., Kenis, G., Bosmans, E., De Meester, I., Benoy, I., Neels, H., Demedts, P., Janca, A., Scharpe, S., Smith, R.S.,
1998. The effects of psychological stress on humans: increased production of pro-inflammatory cytokines and a Th1-like response in stress-induced anxiety. Cytokine 10, 313-318.

McEvoy, J.W., Nasir, K., DeFilippis, A.P., Lima, J.A., Bluemke, D.A., Hundley, W.G., Barr, R.G., Budoff, M.J., Szklo, M., Navas-Acien, A., Polak, J.F., Blumenthal, R.S., Post, W.S., Blaha, M.J., 2015. Relationship of cigarette smoking with inflammation and subclinical vascular disease: the multi-ethnic study of atherosclerosis. Arterioscler. Thromb. Vasc. Biol. 35, 1002-1010.

Moylan, S., Maes, M., Wray, N.R., Berk, M., 2013. The neuroprogressive nature of major depressive disorder: pathways to disease evolution and resistance, and therapeutic implications. Mol. Psychiatry 18, 595-606.

Oladeji, B.D., Gureje, O., 2013. The comorbidity between depression and diabetes. Curr. Psychiatry Rep. 15, 390.

Park, H.S., Park, J.Y., Yu, R., 2005. Relationship of obesity and visceral adiposity with serum concentrations of CRP, TNF-alpha and IL-6. Diabetes Res. Clin. Pract. 69, 29-35.

Raison, C.L., Rutherford, R.E., Woolwine, B.J., Shuo, C., Schettler, P., Drake, D.F., Haroon, E., Miller, A.H., 2013. A randomized controlled trial of the tumor necrosis factor antagonist infliximab for treatment-resistant depression: the role of baseline inflammatory biomarkers. JAMA Psychiatry 70, 31-41.

Riemer, S., Maes, M., Christophe, A., Rief, W., 2010. Lowered omega-3 PUFAs are related to major depression, but not to somatization syndrome. J. Affect. Disord. $123,173-180$.

Romeo, H.E., Tio, D.L., Rahman, S.U., Chiappelli, F., Taylor, A.N., 2001. The glossopharyngeal nerve as a novel pathway in immune-to-brain communication: relevance to neuroimmune surveillance of the oral cavity. J. Neuroimmunol. 115, 91-100.

Ross, R., 1999. Atherosclerosis - an inflammatory disease. N. Engl. J. Med. 340, 115 126.

Schiepers, O.J., Wichers, M.C., Maes, M., 2005. Cytokines and major depression. Prog. Neuropsychopharmacol. Biol. Psychiatry 29, 201-217.

Schiltz, J.C., Sawchenko, P.E., 2002. Distinct brain vascular cell types manifest inducible cyclooxygenase expression as a function of the strength and nature of immune insults. J. Neurosci. 22, 5606-5618.

Schram, M.T., Sep, S.J., van der Kallen, C.J., Dagnelie, P.C., Koster, A., Schaper, N., Henry, R.M., Stehouwer, C.D., 2014. The Maastricht Study: an extensive phenotyping study on determinants of type 2 diabetes, its complications and its comorbidities. Eur. J. Epidemiol. 29, 439-451.

Schram, M.T., Stehouwer, C.D., 2005. Endothelial dysfunction, cellular adhesion molecules and the metabolic syndrome. Horm. Metab. Res. 37 (Suppl. 1), 49-55.

Sheehan, D.V., Lecrubier, Y., Sheehan, K.H., Amorim, P., Janavs, J., Weiller, E. Hergueta, T., Baker, R., Dunbar, G.C., 1998. The Mini-International Neuropsychiatric Interview (M.I.N.I.): the development and validation of a structured diagnostic psychiatric interview for DSM-IV and ICD-10. J. Clin. Psychiatry 59 (Suppl. 20), 22-33, quiz 34-57.

Sherwood, A., Hinderliter, A.L., Watkins, L.L., Waugh, R.A., Blumenthal, J.A., 2005 Impaired endothelial function in coronary heart disease patients with depressive symptomatology. J. Am. Coll. Cardiol. 46, 656-659.

Stehouwer, C.D., Gall, M.A., Twisk, J.W., Knudsen, E., Emeis, J.J., Parving, H.H., 2002 Increased urinary albumin excretion, endothelial dysfunction, and chronic lowgrade inflammation in type 2 diabetes: progressive, interrelated, and independently associated with risk of death. Diabetes 51, 1157-1165.

Teragawa, H., Fukuda, Y., Matsuda, K., Higashi, Y., Yamagata, T., Matsuura, H., Chayama, K., 2002. Effect of alcohol consumption on endothelial function in men with coronary artery disease. Atherosclerosis 165, 145-152.

Tomfohr, L.M., Martin, T.M., Miller, G.E., 2008. Symptoms of depression and impaired endothelial function in healthy adolescent women. J. Behav. Med. 31, $137-143$.

Valkanova, V., Ebmeier, K.P., Allan, C.L., 2013. CRP, IL-6 and depression: a systematic review and meta-analysis of longitudinal studies. J. Affect. Disord. 150, 736744.

van Sloten, T.T., Schram, M.T., Adriaanse, M.C., Dekker, J.M., Nijpels, G., Teerlink, T., Scheffer, P.G., Pouwer, F., Schalkwijk, C.G., Stehouwer, C.D., Henry, R.M., 2013. Endothelial dysfunction is associated with a greater depressive symptom score in a general elderly population: the Hoorn Study. Psychol. Med., 1-14

van Sloten, T.T., Schram, M.T., Adriaanse, M.C., Dekker, J.M., Nijpels, G., Teerlink, T., Scheffer, P.G., Pouwer, F., Schalkwijk, C.G., Stehouwer, C.D., Henry, R.M., 2014 Endothelial dysfunction is associated with a greater depressive symptom score in a general elderly population: the Hoorn Study. Psychol. Med. 44, 1403-1416.

Vischer, U.M., 2006. Von Willebrand factor, endothelial dysfunction, and cardiovascular disease. J. Thromb. Haemost. 4, 1186-1193.

Vitkovic, L., Konsman, J.P., Bockaert, J., Dantzer, R., Homburger, V., Jacque, C., 2000. Cytokine signals propagate through the brain. Mol. Psychiatry 5, 604-615.

WHO, 2015. <http://www.who.int/mediacentre/factsheets/fs369/en/>.

Willerson, J.T., Ridker, P.M., 2004. Inflammation as a cardiovascular risk factor. In: Circulation 109, II2-II10.

Yudkin, J.S., Stehouwer, C.D., Emeis, J.J., Coppack, S.W., 1999. C-reactive protein in healthy subjects: associations with obesity, insulin resistance, and endothelial dysfunction: a potential role for cytokines originating from adipose tissue? Arterioscler. Thromb. Vasc. Biol. 19, 972-978.

Zunszain, P.A., Anacker, C., Cattaneo, A., Carvalho, L.A., Pariante, C.M., 2011. Glucocorticoids, cytokines and brain abnormalities in depression. Prog. Neuropsychopharmacol. Biol. Psychiatry 35, 722-729. 